\title{
Políticas públicas e agentes culturais: uma análise do Programa Cultura Viva e dos pontos de cultura do Paraná ${ }^{1}$
}

\author{
Érico Massoli T. Pereira²
}

- Enviado em 20/02/2016

- Aprovado em 30/05/2016

\section{RESUMO}

Esta pesquisa pretende analisar em que medida o fomento cultural instituído pelo poder público induziu o desenvolvimento do campo cultural configurado a partir do programa Cultura Viva. Isto é, a partir de entrevistas semiestruturadas com os agentes de organizações de sete municípios do Paraná, busca-se compreender a relação entre poder público e dez organizações da sociedade civil contempladas como Pontos de Cultura, no período de 2005 a 2013, analisando a repercussão dessa política cultural nas práticas culturais, nas relações institucionais, bem como na produção e no financiamento cultural das diversas associações. Procura também compreender as reflexões de um conjunto de agentes culturais sobre a gestão do programa Cultura Viva e as políticas públicas de cultura.

Palavras-chave: Agentes culturais. Pontos de Cultura do Paraná. Programa Cultura Viva. Políticas públicas de cultura.

\section{INTRODUÇÃO}

O presente artigo busca compreender a relação entre poder público e entidades do Paraná contempladas como Pontos de Cultura, no período de 2005 a 2013, pelo Programa Nacional de Cultura, Educação e Cidadania - Cultura Viva ${ }^{3}$. Isto é, procurei entender em que medida o fomento vinculado ao Ministério da Cultura e algumas Secretarias Municipais de Cultura do Paraná

\footnotetext{
${ }^{1}$ Dissertação de mestrado defendida em 2013 sob orientação do Professor Doutor Alexandro Dantas Trindade e coorientação da Professora Doutora Maria Tarcisa Silva Bega no Programa de Pós-Graduação em Sociologia da UFPR. Versão na íntegra disponível em http://www.humanas.ufpr.br/portal/pgsocio/files/2013/09/R-D-ERICO-MASSOLI2011-2013.pdf

${ }^{2}$ Mestre em Sociologia. E-mail: ericomassoli@gmail.com

${ }^{3} \mathrm{O}$ programa Cultura Viva foi elaborado e implantado no início da gestão de Gilberto Gil à frente do Ministério da Cultura, e foi regulamentado pelas Portarias MinC n 156 e nº 82, de 06 de julho de 2004 e de 18 de maio de 2005 respectivamente, pelo Ministério da Cultura - MinC.
} 
repercutiram nas práticas de um conjunto de indivíduos e entidades empenhados na constituição de manifestações culturais.

O programa Cultura Viva, foi elaborado e implantado no início da gestão de Gilberto Gil à frente do Ministério da Cultura, ainda no primeiro mandato do ex-presidente Luiz Inácio Lula da Silva. Este programa envolveu um conjunto de diretrizes divididas em cinco eixos de ação, tais como: 1. Agentes Cultura Viva, 2. Griôs, 3. Escola Viva, 4. Cultura Digital e os 5. Pontos de Cultura, sendo este último a principal e mais reconhecida referência do programa, cujo objetivo visava articular todas as demais diretrizes numa única frente de ação. Dentre suas várias metas, segundo o Ministério da Cultura, o programa objetiva "impulsionar e conectar ações culturais já existentes", tornando suas atividades mais visíveis e reconhecidas no cenário cultural, e contemplando grupos e manifestações culturais até então periféricos e não consagrados nos mercados culturais, bem como propostas culturais não contempladas por políticas públicas. Em vigência desde 2004, o programa Cultura Viva contemplou mais de 3.703 entidades culturais como Pontos de Cultura, em pelo menos 1.122 municípios do Brasil ${ }^{4}$, dentre os quais, pelo menos setenta e oito desses pontos estão localizados no Paraná. Devido à abrangência nacional do programa, e para cumprir com os objetivos da pesquisa, delimitei o universo investigado ao conjunto de dez entidades culturais contempladas no estado do Paraná. Vejamos no mapa abaixo a distribuição dos Pontos de Cultura pelos municípios brasileiros, o que pode demonstrar a amplitude nacional e variedade de Pontos de Cultura reconhecidos pela política pública formulada pelo MinC.

\section{FIGURA 1 - Mapa dos Municípios com Pontos de Cultura em dezembro de 2007}

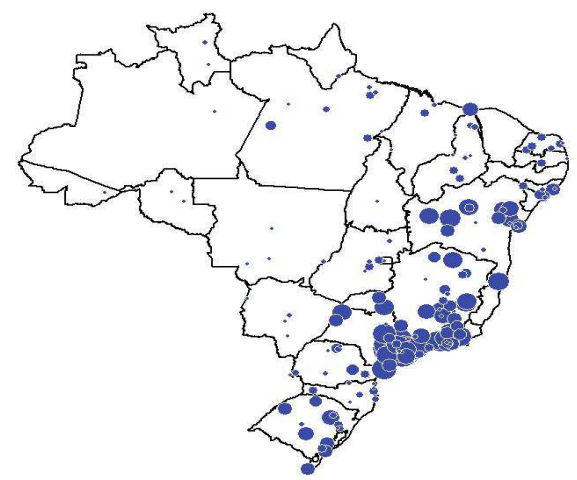

\footnotetext{
${ }^{4}$ Informação acessada no site do Ministério da Cultura: http://www.cultura.gov.br/cultura-viva1.
} 
Com base nessa diversidade de ações, municípios e estados que compõem a rede, somado à variedade de linguagens artísticas utilizadas pelos Pontos de Cultura, é possível perceber a diversidade de atividades promovidas pelo programa, como podemos observar no gráfico abaixo:

\section{GRÁFICO 1 - Atividades Desenvolvidas nos Pontos de}

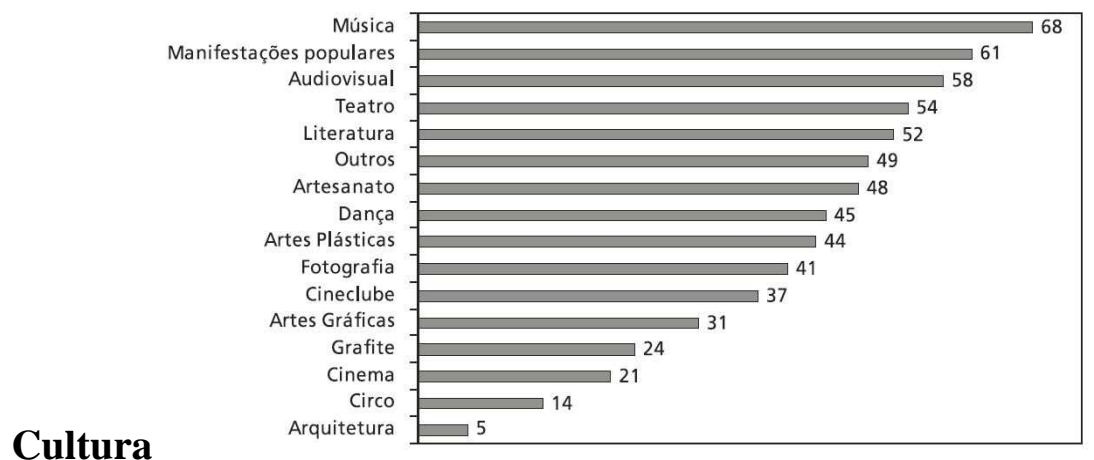

Fonte: IPEA (2010, p. 58).

Além disso, entre os aspectos mais relevantes dessa política governamental consta a pluralidade e diversidade de projetos contemplados pelo programa a partir da referência à diversidade de linguagens artísticas e manifestações populares. Por linguagem artística entende-se as sete modalidades consagradas no meio artístico, tais como música, dança, artes plásticas/visuais, teatro, circo, literatura e audiovisual. Por sua vez, a compreensão de manifestações populares aqui apresentada trata de toda e qualquer manifestação cultural (periférica, comunitária ou popular) não compreendida como cultura erudita.

\section{Algumas Considerações de Caráter Metodológico}

O artigo está circunscrito ao campo das políticas públicas de cultura e desenvolvimento. E para compreender este amplo universo das práticas culturais, formas de organização, bem como seu relacionamento com o poder público, procurei investigar as ações dessas entidades através da narrativa apresentada pelos seus próprios agentes. 
Assim sendo, busquei analisar as atividades desses Pontos de Cultura e sua repercussão na manutenção de um conjunto de agentes propensos a trabalhar com as práticas culturais de forma permanente, financiamento, gestão e recursos materiais. Em seguida, exponho os pressupostos, perspectivas e a concepção do programa Cultura Viva, bem como sua expectativa de ruptura com as chamadas Leis de incentivo à cultura.

Quanto as entrevistas, busquei garantir que os entrevistados se expressassem abertamente. A técnica de entrevistas semi-estruturadas auxiliou a coleta de dados junto aos agentes dos dez Pontos de Cultura, sendo ao total cinco mulheres e nove homens; sendo que dez estão na faixa etária entre 30 e 49 anos e quatro entre 50 e 65 anos.

A definição dos agentes e entidades pesquisados foram considerados a partir da pluralidade dos projetos contemplados como Pontos de Cultura - seja pela variação das linguagens artísticas, manifestações da cultura popular, tecnologias de comunicação, prática da economia solidária e/ou devido a tratar-se de movimentos de contestação. Também foram levados em consideração o tempo de atuação, o nível de institucionalização da associação, a origem do edital e a localização geográfica das entidades.

Além disso, vale atentar para os três entes públicos ${ }^{5}$ responsáveis pela celebração dos convênios com a sociedade civil: Ministério da Cultura (MinC), Fundação Cultural de Curitiba (FCC) e Secretaria de Cultura de São José dos Pinhais (SMC). A não entrada do Governo do Paraná na gestão do Programa Cultura Viva forçou conveniamentos diretos do MinC com os dois municípios, restringindo a premiação aos seus respectivos limites territoriais. Para facilitar a compreensão do campo pesquisado, sintetizei na tabela abaixo o conjunto das entrevistas realizadas.

$5 \quad$ Algum tempo depois, em 2013, a Fundação Cultural de Foz do Iguaçu lançaria edital para 9 Pontos de Cultura e, em 2014, abriria seleção pública para mais 5 entidades. 


\section{QUADRO 1 - Entrevistas Realizadas}

\begin{tabular}{|c|c|c|c|}
\hline Entidade & Convenente & Entrevistas & Município \\
\hline Associação de Cultura Popular Mandicuera & $\mathrm{MinC}$ & $31 / 10 / 2012$ & Paranaguá / Ilha dos Valadares \\
\hline Projeto Olho Vivo & $\begin{array}{l}\text { MinC } \\
\text { FCC }\end{array}$ & $\begin{array}{l}17 / 04 / 2012 \\
29 / 05 / 2012\end{array}$ & Curitiba \\
\hline $\begin{array}{l}\text { CEFURIA - Centro de Formação Urbano Rural } \\
\text { Irmã Araújo }\end{array}$ & MinC & $\begin{array}{l}19 / 04 / 2012 \\
18 / 06 / 2012\end{array}$ & Curitiba \\
\hline $\begin{array}{c}\text { IDDHEA - Instituto de Defesa dos Direitos } \\
\text { Humanos }\end{array}$ & FCC & $16 / 05 / 2012$ & Curitiba \\
\hline Companhia TripCirco & FCC & $\begin{array}{l}18 / 04 / 2012 \\
15 / 06 / 2012\end{array}$ & Curitiba \\
\hline Centro de Estudos da Cultura Afro-brasileira & SMC & $28 / 04 / 2012$ & São José dos Pinhais \\
\hline $\begin{array}{c}\text { FUNCAC - Fundação Cultural e Artística de } \\
\text { Cambé }\end{array}$ & $\mathrm{MinC}$ & $28 / 02 / 2013$ & Cambé \\
\hline Associação de Proteção à Arte e à Cultura (APAC) & $\mathrm{MinC}$ & $01 / 03 / 2013$ & Sertanópolis \\
\hline Escola Milton Santos (MST) & MinC & $\begin{array}{l}01 / 03 / 2013 \\
01 / 03 / 2013\end{array}$ & Maringá \\
\hline Companhia de Teatro Amadeus & MinC & $20 / 02 / 2013$ & Foz do Iguaçu \\
\hline
\end{tabular}

Se considerarmos o processo de descentralização do programa Cultura Viva, perceberemos que é a partir de 2008 que houve sua expansão. Desde então teremos a substituição gradual dos convênios (do MinC) com organizações da sociedade civil por convênios diretos com estados e municípios da Federação. Sendo assim, os governos estaduais e municipais que assinaram o pacto federativo passaram a definir, nos editais lançados por eles, o número total de Pontos de Cultura a serem contemplados, criando suas respectivas redes locais e regionais. Na visão do Ministério da Cultura, "este vínculo constitui um elemento de estabilização, fortalecimento e continuidade das ações e atividades concernentes aos programas do MinC.

Curiosamente, a participação do Paraná, através da Secretaria de Estado da Cultura, foi inexistente, pois não assinaram convênio para implementar 150 Pontos de Cultura diretamente com o Ministério da Cultura. A falta de visão da ex secretária Vera Mussi, somado à falta de vontade política do governo Requião, que teria de aportar um terço dos valores para as entidades culturais, além de comprometer os direitos culturais da população, inviabilizaram o benefício para o conjunto dos 399 municípios paranaenses prejudicando, sobretudo, as cidades de pequeno porte que 
dificilmente conseguirão instituir um convênio direto com o MinC. A situação é tão crítica que, se analisarmos os 16 anos das gestões de Jaime Lerner e Roberto Requião à frente do governo do Paraná, sequer conseguiram manter funcionando o conselho e o fundo estadual de cultura, afetando, inclusive, a lei estadual de incentivo a cultura que, embora tenha maior apelo comercial, tampouco foi regularizada.

\section{O Programa Cultura Viva}

Sua elaboração se deu a partir do Ministério da Cultura com adesão de governos estaduais, municipais, autarquias e de setores da sociedade civil organizada - na forma de Organizações não Governamentais de caráter cultural, social, educacional e ambiental -, os quais disputam entre si o direito de acessar e usufruir dos fundos públicos federais em seus respectivos territórios. Segundo as formulações do Instituto de Pesquisa Econômica Aplicada (IPEA),

o programa Cultura Viva visa garantir os direitos culturais ${ }^{6}$ e construir a democracia cultural $^{7}$. Atua no estímulo a circuitos cujos agentes culturais principais são associações periféricas e comunitárias que, sem políticas deste tipo, não ganhariam visibilidade e nem receberiam apoio público $(2010$, p. 14).

O programa tem como base as atividades desenvolvidas pelos Pontos de Cultura, como se esses sedimentassem o programa articulando todas as demais diretrizes do Cultura Viva num único plano de ação. Quer dizer,

(...) o Cultura Viva é uma rede horizontal de articulação, recepção e disseminação de iniciativas culturais inovadoras, e o Ponto de Cultura é a ponta desta rede, um organizador da cultura em nível local, um centro de referência para novas conexões em rede. Enquanto o Cultura Viva pode ser identificado como uma macrorrede, o Ponto de Cultura pode ser definido como uma microrrede. (2010, p. 28).

6 Os direitos culturais devem garantir aos indivíduos e às coletividades o direito à criação, à fruição, à difusão de bens culturais, além do direito à memória e à participação nas decisões das políticas culturais. (Idem, p. 11).

7 Como um conjunto de eventos que envolve distribuições de bens, oportunidades, participação na criação e em fluxos de decisão, se irradia para os processos contínuos de desenvolvimento. (Ibidem, p. 15). 
Segundo a concepção oficial, o programa se caracteriza como uma política de "mobilização e encantamento social sendo concebida como uma rede orgânica de gestão, agitação e criação cultural". Célio Turino (2009, p. 64) afirma que o "Ponto de Cultura é um conceito de política pública. São organizações culturais da sociedade que ganham força e reconhecimento institucional ao estabelecer uma parceria, um pacto, com o Estado". Ainda segundo Turino,

autonomia, protagonismo, empoderamento, gestão em rede, conhecimentos livres, software livre, cultura digital, trabalho compartilhado, partilha, generosidade intelectual, tradição griô. São conceitos e práticas que estão presentes na militância de gestores dos Pontos de Cultura de todo o Brasil. (...) Um Ponto de Cultura que se envolve pouco com as ações do programa tem mais dificuldades em dar o salto qualitativo em seu trabalho, que pode até ter uma (relativa) eficácia em sua comunidade, mas se o grupo continua como um ponto isolado, o papel do programa terá sido, no máximo, de um bom "transferidor" de recursos públicos (2009, p. 89).

Como não existe uma receita exclusiva de como atuar e de quais conteúdos apresentar, o Ministério da Cultura afirma que

em lugar de determinar ou impor ações e condutas, o programa estimula a criatividade, propiciando o resgate da cidadania pelo reconhecimento da importância da cultura produzida em cada localidade. O efeito é o envolvimento intelectual e afetivo da comunidade, motivando os cidadãos a criar, participar e reinterpretar a cultura, aproximando diferentes formas de representação artística e visões de mundo.

Os Pontos de Cultura são entidades privadas sem fins lucrativos, reconhecidas e apoiadas financeiramente por intermédio de um convênio. Recebem, em média, R \$ 180 mil reais, da União, Estados ou Municípios, para desenvolver suas atividades, compra de material, equipamento multimídia, contratação de profissionais, em aproximadamente 3 parcelas, com base em um plano de trabalho aprovado em edital público federal, estadual ou municipal.

Por fim, Turino afirma que "ao concentrar sua atuação nos grupos historicamente alijados das políticas públicas, o Ponto de Cultura potencializa iniciativas já em andamento, criando condições para um desenvolvimento alternativo e autônomo" (2009, p. 70), o que se traduz por uma tentativa de abranger um amplo setor emergente da sociedade, e não apenas privilegiar 
comunidades artísticas e culturais já consagradas. De acordo com as diretrizes do Cultura Viva, seu público alvo compõe-se de

populações de baixa renda, habitantes de áreas com precária oferta de serviços públicos, tanto nos grandes centros urbanos como nos pequenos municípios; Adolescentes e jovens adultos em situação de vulnerabilidade social; Estudantes da rede básica de ensino público; Professores e coordenadores pedagógicos da educação básica; Habitantes de regiões e municípios com grande relevância para a preservação do patrimônio histórico, cultural e ambiental; Comunidades indígenas, rurais e remanescentes de quilombos; Agentes culturais, artistas e produtores, pesquisadores, acadêmicos e militantes sociais que desenvolvem ações de combate à exclusão social e cultural (MINC).

Tal política pode ser concebida como tributária de preceitos democráticos ao valorizar o fazer cultural das pessoas e ter como diretrizes relações horizontais e contemplar a diversidade de agentes culturais envolvidos. Seus próprios formuladores enfatizam o fato de que, ao longo das últimas décadas, as políticas para a cultura haviam dado exagerado enfoque na produção e comercialização da indústria cultural por intermédio das leis de incentivo, ao passo que os objetivos do Cultura Viva seriam, ao contrário:

ampliar e garantir acesso aos meios de fruição, produção e difusão cultural; Identificar parceiros e promover pactos com atores sociais governamentais e não governamentais, nacionais e estrangeiros, visando um desenvolvimento humano sustentável, no qual a cultura seja forma de construção e expressão da identidade nacional; Incorporar referências simbólicas e linguagens artísticas no processo de construção da cidadania; Potencializar energias sociais e culturais, dando vazão à dinâmica própria das comunidades e entrelaçando ações e suportes dirigidos ao desenvolvimento de uma cultura cooperativa, solidária e transformadora; Fomentar uma rede horizontal de "transformação"; Promover a cultura enquanto expressão e representação simbólica, direito e economia (MINC)7.

\section{A Lei Rouanet e a Cultura Viva}

Qualquer estudo que visa compreender mecanismos de incentivo à cultura necessariamente implica em reconhecer limites, alcances e desempenho de forças sociais e agentes hegemônicos e periféricos, bem como a produção, circulação e recepção de distintos bens simbólicos de extratos socioculturais situados em posições desiguais na sociedade. Neste sentido, compreender os instrumentos de fomento a produtos culturais massificados, artesanais ou destinados às elites, assim como seus respectivos mercados, significa compreender também a arena de disputas a bens econômicos, políticos e simbólicos subjacentes ao próprio conflito social. 
Buscando uma compreensão histórica das leis de mercado no campo das artes, segundo Raymond Williams (2011), é difícil dissociar o "patronato" e o mercado, assim como o artista e a obra de arte (mercadoria) produzida, em relação a qualquer tipo de troca. Nesse caso, tanto o "patronato" público como o privado tem como "característica definidora de todas as relações sociais a situação privilegiada do patrono". Enquanto essa figura autoritária do patrono subsistir, é ele e sempre ele, portanto, quem definirá como, quanto e o que apoiar no âmbito da arte e cultura. Segundo Williams,

historicamente, existe um longo período de sobreposição entre relações sociais de patronato e de mercado nas artes. Em princípio, porém, elas podem ser prontamente diferenciadas. A produção para o mercado implica a concepção da obra de arte como mercadoria, e do artista, ainda que ele possa definir-se de outra forma, como um tipo especial de produtor de mercadorias. Mas há, por outro lado, fases de produção de mercadoria essencialmente diferentes. Todas elas implicam produção para simples troca monetária; a obra é posta à venda e é comprada e, desse modo, possuída (Ibidem, p. 44).

No Brasil, a abertura política de 1985 iniciou um novo período de transição instituindo maior regulamentação do "bem cultural" no mercado das artes através da criação da Lei Federal de Incentivo à Cultura, isto é, a Lei Sarney, promulgada pelo ex-presidente em julho de 1986. Além disso, apesar do governo Sarney ter criado o Ministério da Cultura em 1985, foi muito grande a instabilidade política dentro do MinC. É a partir daí que se fortalece a compreensão do "balcão de negócios" na gestão da cultura. No entanto, segundo Calabre,

esse cenário teve sua insegurança reduzida devido à constituição de 1988: por meio do artigo 215, ficou estabelecido que o Estado garantirá "a todos o pleno exercício dos direitos culturais e o acesso às fontes da cultura nacional, e apoiará a valorização e a difusão das manifestações culturais". Além disso, a nova Constituição garantiu também maior autonomia para os municípios, que gradativamente viriam a desempenhar uma função estratégica dentro do processo de gestão e de formulação de políticas culturais (CALABRE, 2009, p. 105).

A partir da Constituição Federal de 1988, portanto, deflagrou-se um novo rearranjo institucional do Estado brasileiro e, desde então, podemos compreender a associação ao direito de produzir, fruir e transmitir bens e produções culturais, bem como reconhecer formas diferenciadas de vida. Dessa forma, segundo o artigo 215 da Carta Magna, é dever do Estado a tutela do direito cultural, garantindo sua realização por meio de ações e políticas públicas. 
A própria Lei Federal de Incentivo à Cultura que buscava inovar na arrecadação orçamentária da cultura a partir do mecanismo de renúncia fiscal, e após receber inúmeras críticas, viria a ser extinta e republicada por Fernando Collor no final de 1991, já rebatizada como Programa Nacional de Apoio à Cultura, mais conhecida como Lei Rouanet.

Em seguida, o governo FHC a aperfeiçoaria introduzindo o "dirigismo privado", com toques de crueldade no combalido orçamento, visto que o governo federal diminuiria sistematicamente os investimentos na área da cultura. A década 1990, não por acaso, foi um período de evidente hegemonia do preceito neoliberal, com a redução do papel do Estado e privatização irrestrita da coisa pública. Tanto é verdade que a gestão FHC cunhou a expressão "cultura como um bom negócio ${ }^{8 "}$, fazendo desse recurso, quase exclusivamente, a única fonte de financiamento para a cultura, que acabou tornando-se símbolo da sua administração. É importante salientar que vários estudos do período (1995-2002) apontaram distorções, na lei de incentivo, advindas das revisões implementadas a partir de 1995. Além disso, falta critério para o uso do dinheiro público e maior investimento por parte dos patrocinadores privados, além da super concentração dos recursos na região sudeste do país. Observando essas disfunções da Lei Rouanet, fica claro e muito atual o que Celso Furtado escreveu: é exatamente na diversidade das regiões do Brasil que estão as raízes de nossa riqueza cultural. Mas a preservação dessa diversidade e riqueza exige que o desenvolvimento material se difunda por todo o território nacional (1984, p. 46).

Apesar de todas as críticas e distorções, o incentivo fiscal é uma modalidade de fomento legítima do Estado desde que ele garanta um desenvolvimento equânime do segmento beneficiado e certifique-se dos benefícios auferidos pela população ao final de sua vigência. Além disso, essa intervenção deve ser mesclada com outras modalidades de fomento que minimizem as distorções regionais equilibrando também a distribuição orçamentária e o acesso e a produção cultural para os agentes emergentes.

Vale ressaltar que embora o Cultura Viva também tenha, em alguns aspectos, a preocupação de inserir os pequenos agentes culturais no mercado, contudo, seu enfoque principal é estabelecer a cidadania cultural enquanto ferramenta de emponderamento das pessoas para que elas mesmas criem seus próprios processos e fins culturais, quando possível e necessário. O pesquisador Néstor García Canclini faz ponderações à mercantilização afirmando que, hoje,

\footnotetext{
8 Em vários aspectos, as leis de incentivo retiram o poder de decisão do Estado e o colocam nas mãos da iniciativa privada - revigorando o dirigismo privado e o marketing cultural - embora a dotação orçamentária utilizada seja majoritariamente pública.
} 
interessam mais os bens culturais - objetos, lendas, músicas - que os agentes que os geram e consomem. Essa fascinação pelos produtos, o descaso pelos processos e agentes sociais que os geram, pelos usos que os modificam, leva a valorizar nos objetos mais sua repetição que sua transformação $(2011$, p. 211).

O programa Cultura Viva certamente levará vantagem sobre os mecanismos de incentivo fiscal, se levarmos a sério as formulações der Charles Taylor (2006), que diz que deveríamos considerar a qualidade das democracias modernas e de suas políticas públicas a partir do tratamento inclusivo dado às minorias étnico culturais, visto que a convivência cultural é indispensável para todos os indivíduos, sobretudo, para os que pertencem às minorias discriminadas e marginalizadas.

O autor está chamando à atenção para a importância do "reconhecimento" o qual, tendo uma base cultural, comunitária e linguística, garantindo a proteção das culturas minoritárias mediante políticas públicas como a que estamos estudando. Furtado, por sua vez, argumenta que

todos os povos lutam para ter acesso ao patrimônio cultural comum da humanidade, o qual se enriquece permanentemente. Resta saber quais serão os povos que continuarão a contribuir para esse enriquecimento e quais aqueles que serão relegados ao papel passivo de simples consumidores de bens culturais adquiridos nos mercados (1984, p. 25).

A distinção entre as políticas começa a ficar mais clara quando verificamos que a lei de incentivo não se preocupa em garantir condições para a população alcançar a posição de criadora, preocupando-se preferencialmente em criar novos públicos e novos consumidores. Por sua vez, a partir do Cultura Viva, os cidadãos são estimulados a ter tanto o acesso como a garantia de produção de bens simbólicos. Aqui entramos, segundo Marilena Chauí, numa "política cultural definida pela ideia de cidadania cultural, em que a cultura não se reduz ao supérfluo, ao entretenimento, aos padrões do mercado, à oficialidade doutrinária, mas se realiza como direito de todos os cidadãos (CHAUÍ, 2006, p. 138).

Levando a discussão para a perspectiva econômica, embora as disparidades sejam enormes podemos identificar aproximações e distanciamentos entre as leis de incentivo e a política dos Pontos de Cultura. O programa Cultura Viva tem entre seus méritos a capacidade de promover arte e cultura, com alta ou baixa performance no mercado das artes. No entanto, verifica-se entre seus fazedores culturais a dificuldade de transformar o que produzem em mercadoria, sendo de certa maneira, invisibilizados pela indústria cultural. Assim sendo, essa divisão entre os produtores culturais com "sucesso comercial ou mundano" é algo inerente ao mercado simbólico e "o próprio 
não sucesso é em si ambíguo, já que pode ser percebido seja como escolhido, seja como sofrido" (BOURDIEU, 1996, p. 248).

Apesar de possuir um orçamento bem modesto em relação a Lei Rouanet, segundo o IPEA, os Pontos de Cultura beneficiaram 8 milhões e 400 mil pessoas no país, entre participantes diretos e indiretos das atividades, em aproximadamente 5 anos de implementação do programa. Para se ter uma ideia da importância do programa no MinC, após sua criação em 2004, em 2007 já era o maior programa finalístico do Ministério da Cultura, com 28,7\% do orçamento (IPEA, 2010, p. 43).

Convém relembrar que há aproximadamente vinte anos atrás, até hoje, a Lei Rouanet não minimizou as distorções e desigualdades na distribuição dos recursos. Embora as cifras sejam muito superiores ao orçamento do Cultura Viva, seus benefícios acabam se concentrando em artistas consagrados do eixo Rio-São Paulo.

Por outro lado, se avaliarmos a simples transferência de recursos e compararmos com o processo até aqui desenvolvido pelas leis de incentivo a cultura, ficará mais claro que o programa Cultura Viva, sequer repassa recursos com eficiência - garante-se financiamento a produtores populares, mas a sua dinâmica de gestão é rígida e restritiva e os valores repassados, muito modestos. Isto acaba inviabilizando muitas associações comunitárias rurais e urbanas sem condições materiais e capacitação técnica para enfrentar procedimentos licitatórios - para a maioria dos gestores e fazedores culturais, a principal barreira para a ampliação e consolidação do programa.

Por sua vez, as leis de incentivo permitem captações maiores para os grupos profissionalizados e com maior agilidade e simplicidade de gestão e prestação de contas - os projetos são mais fáceis de serem habilitados, mas existe um grande funil na captação, muito associado à figura de intermediação do captador, que restringe o acesso aos recursos junto às empresas financiadoras (em sua maioria do eixo Rio-São Paulo).

\section{Financiamento e Dilemas da Gestão Cultural}

Entre os principais méritos dos Pontos de Cultura, consta o reconhecimento de variados atores e o financiamento de organizações culturais já existentes e muitas vezes invisibilizadas. Podemos falar de manifestações artísticas, culturais, educativas e ambientais, em diálogo com 
movimentos de trabalhadores, movimentos urbanos e rurais, de crianças, jovens e idosos, com debates de gênero, LGBT, internet, tecnologias e software livre, midialivrismo, economia solidária, comunicação e educação popular, que reunidas numa mesma ação podem fortalecer os direitos culturais de qualquer programa público.

Tendo como referência esse mosaico de ações, resta analisar o que de fato ocorreu na implementação dos Pontos de Cultura, permitindo o confronto entre o que foi formulado nos gabinetes ministeriais e o que foi, de fato, possível por em prática na sociedade. Haja vista que boa parte das políticas públicas tem grande dificuldade de alinhar teoria e prática. Tanto que, na investigação realizada pelo IPEA, constatou-se que "a filosofia e as concepções do programa foram bem valoradas. Em contrapartida, quesitos como implementação e execução foram objeto de crítica" (2010, p. 37).

Com base nisso, é possível discutir a mudança de perspectiva que o referido programa inseriu no segmento cultural brasileiro e seus desdobramentos no campo cultural. Nesse curto período de tempo, a partir do protagonismo governamental, o programa passou a gozar de legitimidade entre os fazedores culturais, a despeito da ineficiência do Estado em gerir seus processos e recursos, bem como por suas dificuldades de atendimento a entidades com reduzida capacidade institucional.

Tendo em vista que o convênio do Ponto de Cultura tem um prazo de vigência, com início, meio e fim estabelecidos, objetivos e resultados esperados, a continuidade dos trabalhos, ou melhor, a manutenção do financiamento público, tem relação direta com a capacidade desses agentes e entidades em conseguir lidar com a burocracia estatal, em especial, a gestão e a prestação de contas desses repasses dentro das normas legais vigentes para, quem sabe, disputar novo edital público de fomento ou caminhar pelas próprias pernas. Do conjunto de dez entidades aqui investigadas, $70 \%$ foram criadas ainda nos anos 2000, 1 na década de 1990 e 2 na década de 1980. Entre as mais antigas, constam o CEFURIA (fundado em 1981), e a Secretaria de Cultura de Cambé (fundada em 1983), a qual criou, em 2005, a FUNCAC com o objetivo explícito de flexibilizar/agilizar a capacidade criadora da prefeitura do município. É interessante observar que a longevidade de algumas entidades não foi fator determinante do sucesso na gestão do convênio.

Por outro lado, em diversas situações a institucionalização jurídica ocorre muito tempo após a criação efetiva da entidade, como podemos verificar com o CECAB de São José dos Pinhais, 
criado informalmente em 1998 e formalmente apenas em 2007. A concentração de entidades criadas nos anos 2000 reforça o fenômeno recente da personalização jurídica, fator que as habilita a disputar recursos escassos na iniciativa pública e privada. Mas nem sempre foi assim. Embora o Cultura Viva privilegie a transferência de recursos para entidades formalizadas, esse fenômeno não é exclusividade apenas da gestão cultural, visto que as reformas neoliberais da segunda metade da década de 1990 difundiram essa prática para todas as instâncias da federação. Vejamos abaixo o gráfico:

\section{GRÁFICO 2 - Ano de Fundação da Entidade}

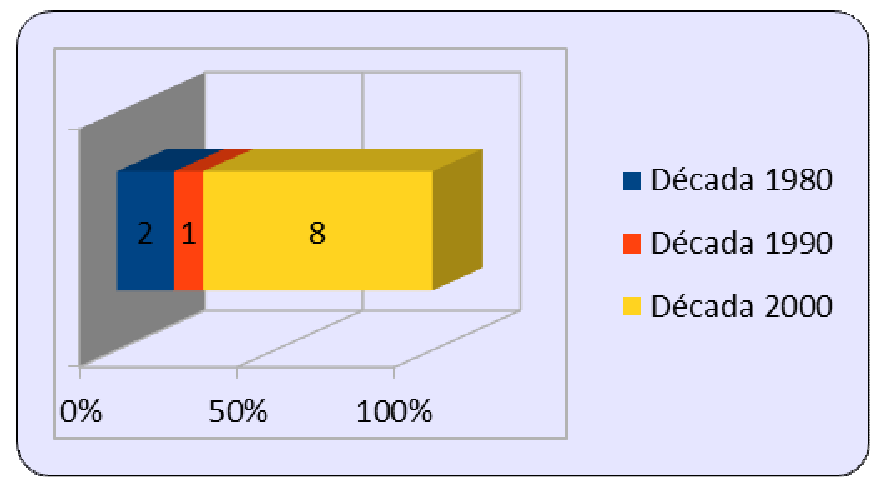

Fonte: Dados do autor.

Do universo de entidades investigadas, parte delas não possuem infra-estrutura satisfatória. Dessas, todavia, a FUNCAC é a única que possui espaços descentralizados, sendo uma delas patrimônio próprio da prefeitura da cidade de Cambé e as demais alugadas em bairros periféricos. A situação da Escola Milton Santos, em Maringá, é mais complexa, pois seu terreno foi fruto de uma concessão da prefeitura há mais de vinte anos havendo tensão permanente sobre a sede movimento. Vejamos abaixo o detalhamento no gráfico: 


\section{GRÁFICO 3 - Espaço Físico da Entidade}

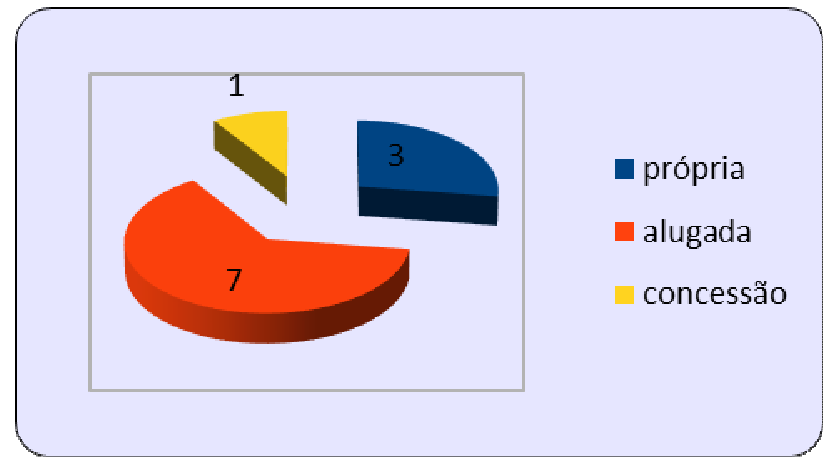

Fonte: Dados do autor.

\section{A "burocratização" da cultura}

Nesse subitem analisarei a lógica controladora e não democrática do Estado e as diversas facetas da burocracia, cujos agentes culturais diariamente são vítimas. Afinal, embora haja uma abertura considerável do poder público, é evidente o descompasso entre o Estado e culturas não hegemônicas, evidenciando-se o caráter excludente existente entre aquele e certas expressões da sociedade.

Nessa situação, Karl Marx ajuda a explicar certas ingerências estatais, fazendo-nos crer que o procedimento burocrático realmente é uma espécie de violência contra a sociedade. Essa "hierarquia do saber" funciona exclusivamente para si mesma sem se preocupar com a real finalidade do serviço público. Não seria despropositado concluir que o procedimento burocrático se fantasia de Estado e que, portanto, "o espírito geral da burocracia é o segredo, o mistério, guardado no seu seio pela hierarquia e no exterior pelo seu caráter de corporação fechada" (MARX, 1983, p. 72).

Buscando aproximar a discussão das políticas públicas no Brasil, verifica-se um aprisionamento da administração pública "entre mecanismos jurídico institucionais (conjunto de leis, regulamentos, jurisdição, instâncias e procedimentos formais) e mecanismos administrativos menores no âmbito do cumprimento de ordens e execução de decisões prévias" (IPEA, 2010, p. 25) insuficientes para o entendimento de boa parte das políticas públicas. Ou seja, prevalece hoje uma discussão jurídica em torno das políticas públicas que tenta restringi-las em um campo do direito, 
sendo que nem mesmo o pensamento jurisdicional tem condições de englobar todas as nuances da política (IPEA, 2010, p. 19). Enfim, percebe-se um certo descolamento da burocracia, uma certa autonomização que se sobrepõe à esfera política, capaz de criar regras próprias, que demandam reformas urgentes nos seus trâmites para recepcionar programas plurais como o Cultura Viva.

A crítica à burocracia é tão recorrente que até mesmo o ex-secretário de Cidadania Cultural do MinC, Célio Turino, tratou de elucidar as limitações impostas por essa modalidade de repasse financeiro. Sobre as possíveis e necessárias reformas na máquina estatal, que até hoje não vieram, é necessário abranger articulações e setores mais amplos da sociedade e do próprio Estado. A pasta da cultura sozinha dificilmente conquistaria tais objetivos, visto que estamos dissertando sobre transformações no topo da pirâmide do poder do Estado Moderno burguês. Segundo Turino,

durante o processo de implantação e acompanhamento dos Pontos há tensão. De um lado, os grupos culturais, apropriando-se de mecanismos de gestão e recursos públicos; de outro, o Estado, com normas de controle e regras rígidas. Essa tensão, de certo modo inevitável, cumpre um papel educativo que, a longo prazo, resultará em mudanças em ambos os campos. O objetivo seria uma burocracia mais flexível e adequada à realidade da vida, assim como um movimento social mais bem preparado no trato das questões de gestão, capacitando-se para melhor acompanhar as políticas públicas e o planejamento de suas atividades específicas (2009, p. 64).

O entendimento de que o Estado tem uma sistemática que inviabiliza iniciativas como o Cultura Viva circula livremente pelos discursos dos fazedores culturais. Coelho (1997, p. 116) reforça essa opinião dizendo que "a cultura organizacional da gestão cultural é específica e de difícil compreensão para a cultura organizacional da administração pública como um todo". Segundo o autor, o Estado ainda é hierarquizado entre "setores nobres" e "setores pobres", onde estaria a cultura, prevalecendo as decisões políticas do primeiro escalão, com forte vínculo mercadológico, sobre os últimos. Conforme estudo do IPEA, é necessário fazer evoluir a discussão e a implementação de um novo marco regulatório para o Cultura Viva:

Em primeiro lugar, deve-se enunciar que o Estado não têm instrumentos jurídicos e de gestão, ou eles não são adequados para suportar, de maneira efetiva, políticas com o desenho e a forma de execução do programa Arte, Cultura e Cidadania - Cultura Viva. Em segundo lugar, afirma-se que é necessário capacitar o programa, dotando-o de instrumentos propícios, de forma que ele persiga objetivos ancorados no texto constitucional e em princípios democráticos (2010, p. 109, grifo nosso). 


\title{
Gestão Estatal versus Compartilhamento
}

O Cultura Viva trouxe uma nova concepção de gestão cultural que, em processo de construção e mutação contínua, prega:

\begin{abstract}
novos parâmetros de gestão e democracia na relação entre Estado e Sociedade. O modelo de gestão precisa ser flexível e moldável e respeitar a dinâmica própria do movimento social. [...] Durante o processo, sem dúvida, haverá uma tensão: por um lado, o movimento social se apropriando de mecanismos de gestão, recursos públicos. Por outro lado, o Estado, com seu aparato burocrático, normas e regras rígidas. A partir desta interação, poderemos construir um novo tipo de Estado, ampliado, que compartilha poder com novos sujeitos sociais, que ouve quem nunca foi ouvido e conversa com quem nunca conversou. (IPEA, 2010, p. 18).
\end{abstract}

Percebemos que, apesar da boa vontade do Governo Federal, o contexto é bastante complexo, afinal, os convênios públicos são conduzidos simultaneamente por três órgãos públicos detentores de distintas capacidades materiais e humanas, e em contextos sociais igualmente diversos, o que resulta em desempenhos heterogêneos.

Apesar da perspectiva mais horizontal dos agentes públicos da gestão do MinC durante o governo Lula, o único padrão percebido na gestão da cultura, que se mantém a despeito das mudanças ministeriais, é a rigidez burocrática percebida por muitas entidades da sociedade civil como um entrave às suas iniciativas. Não raro, atrasos nos repasses, equívocos e incompreensões na gestão orçamentária, tais questões foram, inclusive, identificados anteriormente pelo IPEA na implementação do programa. Ou seja, constata-se,

insuficiência de quadro funcional envolvidos diretamente com a gestão do programa; dificuldades na celebração de convênios, devidas em especial a interpretações divergentes de normas, situação de inadimplência dos proponentes, ou não apresentação de documentação obrigatória; inexistência de norma legal que fundamentasse especificamente o relacionamento do Estado brasileiro com entidades da sociedade civil com baixo nível de organização ou institucionalidade; e insuficiência e inadequação dos fluxos de recursos e dificuldades com relação à coordenação das ações por parte da administração pública (IPEA, 2010, p. 31).

Por outro lado, no que tange à premiação desses agentes culturais, prevaleceu a capacidade deles em obter a informação e formular um projeto de qualidade em tempo hábil para a seleção promovida pelos poderes públicos. Ou seja, diferentemente do dirigismo privado instituído pelas 
leis de incentivo, e da prática de "balcão de negócios" que sempre beneficiou os mesmos produtores culturais, a escolha do critério de editais públicos, longe de solucionar todos os problemas de transparência e acesso, auxiliou nesse novo processo de seleção um pouco mais transparente e democrático.

Sendo assim, ficou bastante claro que, embora o programa não tenha universalizado o acesso, garantiu uma diversificação considerável dos agentes contemplados e uma maior descentralização dos fundos públicos, a começar pelo impedimento de empresas e produtoras privadas de disputarem os referidos editais. Essa informação por si só significa muito, mas não garante toda oportunidade de sucesso tão frequentemente associado ao reconhecimento como Ponto de Cultura.

Além disso, vale lembrar que todos os convenentes tiveram atrasos no repasse dos recursos, inclusive entre as entidades com a execução integral do convênio. Isso deixa claro que o problema não está exclusivamente nas organizações reconhecidas como Pontos de Cultura, mas sim nos procedimentos burocráticos do Estado. Visualizemos abaixo como a duração média dos convênios se prolongaram.

\section{GRÁFICO 4 - Duração dos Convênios}

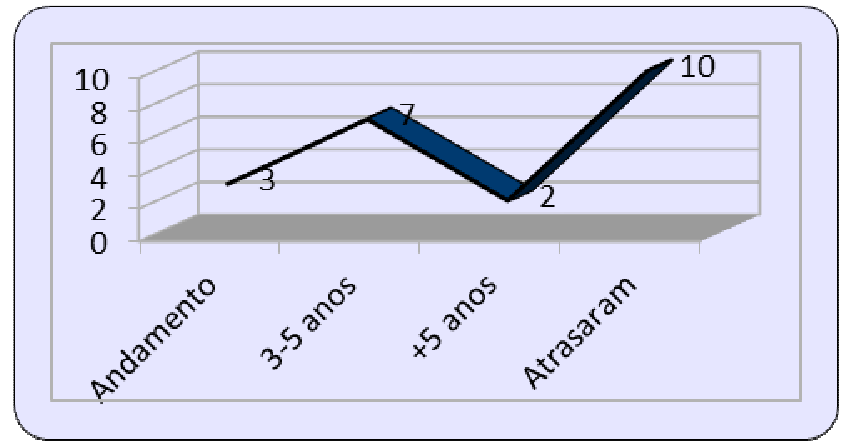

Fonte: Dados do autor.

Entre as principais críticas dos agentes culturais paranaenses constam, sobretudo, os frequentes atrasos dos repasses, o que acaba por desmobilizar os participantes, desvalorizando as 
atividades ofertadas, gerando retrabalho e desgastando a relação com a comunidade atendida. Mais uma vez percebemos um anacronismo entre discurso e prática, pois o simples fato de se utilizar a lei de licitações, tão comum no ramo das empreiteiras bilionárias da construção civil, prejudica boa parte das possibilidades criativas e democrática entre Estado e sociedade civil. A própria perspectiva de se construir um "novo tipo de Estado", nessa relação de tensão, não se concretizou até o momento, isto é, não houve mudança nos marcos regulatórios e muitas entidades, em descompasso com as normas, acabam sendo inviabilizadas pela atuação implacável dos órgãos públicos de fiscalização, entre os quais, em última instância, o Tribunal de Contas da União (TCU).

O próprio Instituto de Pesquisa Econômica Aplicada (2010) já havia feito constatações sobre as limitações do Estado na condução das políticas públicas. Na pasta da cultura, pela falta de memória institucional, orçamento e tradição, o quadro é mais sensível ainda, pois "as políticas públicas são de extrema complexidade, e os técnicos administrativos encontram-se diante de profundas debilidades não apenas para implementá-las, mas também para avaliá-las, dada a ausência de padrões e uniformidades" (IPEA, 2010, p. 27). Continua o instituto afirmando que,

deve-se reconhecer que a implementação de políticas públicas culturais implica construção de instrumentos e qualificação das instâncias administrativas estatais, assim como de suas capacidades, para coordenar e obter a cooperação das instâncias de mercados ou comunitárias para o desenvolvimento de circuitos culturais (IPEA, 2010, p. 25).

O gráfico abaixo ilustra as dificuldades de gestão entre os agentes entrevistados. Mesmo entre os que afirmaram não terem maiores dificuldades de gestão a condução do convênio não foi tranquila, sobretudo, por conta dos atrasos, morosidade e falhas de comunicação frequentes entre as entidades da sociedade civil e o poder público. 


\section{GRÁFICO 5 - Dificuldades de Gestão dos Convênios}

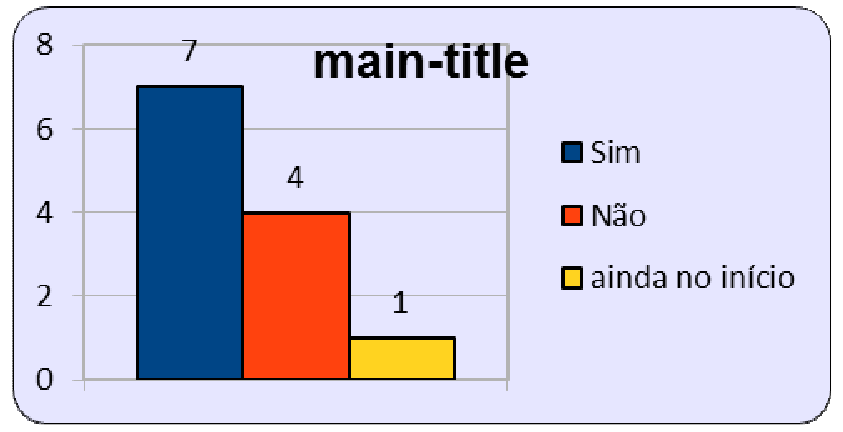

Fonte: Dados do autor.

\section{Aspectos da gestão compartilhada}

É necessário reconhecer o esforço, ao menos do ponto de vista do discurso e da intencionalidade, dos formuladores do Cultura Viva em fazer uma gestão compartilhada. No entanto, na perspectiva legalista e prática, essa formulação carece de respaldo jurídico e político.

Analisemos o Conselho Consultivo, outra instância criada pelo Ministério da Cultura, que deveria cumprir um papel central nessa mediação entre os distintos entes federativos e a sociedade civil.

É um espaço de encontro para troca de saberes que busca reunir representantes do Estado e dos Pontos de Cultura, acadêmicos, mestres da tradição oral e pessoas cujo "saber fazer" e cujo "pensar sobre o fazer" vem nos ensinando e revelando diferentes dimensões de uma cultura que é viva, fluida, que transforma a comunidade e por sua vez é por ela transformada. Seus membros são intelectuais orgânicos que valorizam e defendem a socialização do conhecimento e recriam a função dos intelectuais, conectando-os às lutas políticas dos grupos sociais contemporâneos, e no caso do Brasil, a partir de uma visão descolonizadora. (...) O Conselho passa a fazer parte da vida do Programa em um contexto de descentralização, ao fortalecer redes e compartilhar poderes e responsabilidade e exercitando a cogestão, em que é necessário um espaço para pensar o Programa, encontros regulares para reflexão ação. Não é um espaço estéril, de pensar por, mas um espaço de pensar com, de agregar, proporcionar encontros e reencontros (MINC, 2010, p. 15).

Apesar da proposição ser plural e democrática, na prática, é difícil de comprovar sua efetiva implementação na gestão de Gilberto Gil e Juca Ferreira a frente do Ministério da Cultura. No atual governo Dilma, que teve Ana Buarque de Holanda (ruptura) e em seguida Marta Suplicy na condução política do Ministério, se quer se ouviu falar em "gestão compartilhada" ou "conselho 
consultivo". Com o retorno de Juca Ferreira para o MinC as diretrizes fundantes do programa foram retomadas mas ainda é controverso dizer que a gestão compartilhada está efetivada.

Na prática, portanto, é bem provável que a relação nunca tenha deixado de ser hierárquica e verticalizada, salvo alguma eventual exceção. Vejamos a opinião dos agentes culturais paranaenses sobre o assunto no gráfico abaixo:

\section{GRÁFICO 6 - Gestão Compartilhada nos Convênios nos Pontos de Cultura do Paraná}

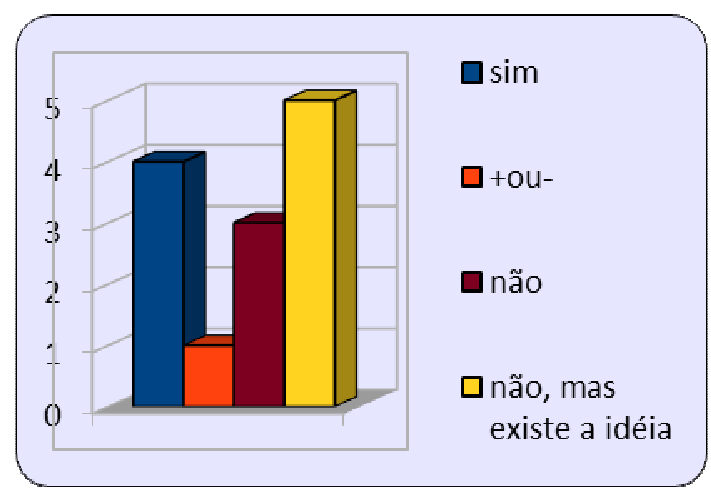

Fonte: Dados do autor.

Durante a realização das entrevistas perguntei aos representantes dos Pontos de Cultura se houve ou se há gestão compartilhada entre o poder público, o Ponto de Cultura e comunidade beneficiada obtendo respostas muito parecidas entre os entrevistados que afirmaram haver a ideia plantada mas que na prática é preciso fazer muita coisa para superar a dificuldade de dialogo entre comunidades e poder público. O grande mérito alcançado com o repasse de recursos é que os coletivos buscaram se aproximar ainda mais de seus entornos comunitários para fazer acontecer o plano de trabalho. Além disso, a dita gestão colaborativa teria vingado mais no campo das instituições coletivas e nas instâncias decisórias internas da própria rede, deixando a desejar na conexão com o Estado incapaz, muitas vezes, de instituir relações mais horizontais e eficazes.

As Teias e Fóruns nacionais e regionais dos Pontos de Cultura estão entre as ações do programa Cultura Viva com maior adesão dos membros dos Pontos de Cultura. Segundo o IPEA, essa ação obteve $91 \%$ de adesão (2010, p. 67), figurando, dessa forma, acima das demais ações do 
programa. Não se sabe exatamente o porque, se por se tratar de uma rede de artistas e agentes culturais, se pela diversidade de apresentações culturais, mas o fato é que por produzirem bens simbólicos e intangíveis tendem a valorizar encontros e intercâmbios culturais nas práticas cotidianas, onde quem sabe faz na hora, com muita inventividade e bom humor. Essa forte necessidade de se mostrar gabarita esses encontros, sendo um momento ímpar sob vários aspectos da criação, articulação e formação.

A gestão compartilhada, portanto, é defendida nos textos conceituais mas as barreiras burocráticas do Estado, a falta de conhecimento sobre a gestão pública por parte de muitos dos Pontos de Cultura ou até mesmo a descontinuidade promovida na era Lula para a $1^{\text {a }}$ gestão de Dilma, fizeram com que todo e qualquer ímpeto da gestão compartilhada na gestão do programa pelo MinC e sociedade civil fossem estremecidas nos últimos anos.

\section{CONSIDERAÇÕES FINAIS}

Cabe elucidar que durante todo o trabalho, busquei compreender em que medida o fomento cultural instituído pelo poder público induziu o desenvolvimento do campo cultural, configurado a partir do Cultura Viva. Tendo em vista que o programa é recente e sua estratégia de implementação ainda ligeiramente tímida, se levarmos em consideração a dimensão geográfica do País e o histórico agudo de exclusão cultural, visto que o universo de organizações premiadas é ainda reduzida, é preciso que o mesmo seja estimulado com aporte financeiro mais robusto pela administração pública, inclusive pelo Governo do Estado do Paraná, promovendo assim uma melhor e maior distribuição dos recursos no território nacional e paranaense.

Ademais, os dados sistematizados e exposto nesse artigo, que também é sustentado pelas análises das entrevistas realizadas, nos faz retornar às indagações formuladas no início desse trabalho para auferir a seguinte conclusão: a despeito das limitações burocráticas e contingenciamento orçamentário, o Cultura Viva tem promovido o reconhecimento de atores até então invisibilizados, bem como está valorizando a diversidade cultural do país. 
Por fim, uma vez que o Programa Cultura Viva se propõe a promover a democracia e a diversidade cultural, visando reverter uma trajetória de não contemplação dos agentes periféricos com políticas públicas de cultura, parece razoável afirmar que o mesmo obteve relativo sucesso nessa primeira parte da jornada.

Vale reforçar que a política dos Pontos de Cultura, à época liderado pelo ex-ministro Gilberto Gil e, atualmente, conduzido pelo Ministro Juca Ferreira, teve atuação pioneira no fomento e apoio às ações culturais. Após 10 anos de espera e muita luta dos fazedores culturais do país, o programa foi reconhecido pelo Congresso Nacional e pelo Poder Executivo e alçou voo de tal forma que a Política Nacional Cultura Viva (lei $\mathrm{n}^{\circ}$ 13.018) foi sancionada pela presidente Dilma em 22 de julho de 2014, simplificando e desburocratizando os processos de prestação de contas e o repasse de recursos para as organizações da sociedade civil. Contudo, como consta da meta do Plano Nacional de Cultura, até 2020, o desafio será abarcar 15 mil Pontos de Cultura atuantes em todo território Nacional.

\section{REFERENCIAS}

CALABRE, Lia. Políticas culturais no Brasil: dos anos 1930 ao século XXI. Rio de Janeiro: Editora FGV, 2009.

CANCLINI, Néstor García. Culturas híbridas: estratégias para entrar e sair da modernidade. São Paulo: Edusp, 2011.

CHAUI, Marilena. Cidadania Cultural - O direito à cultura. $2^{\mathrm{a}}$ ed. São Paulo: Fundação Perseu Abramo, 2006.

FURTADO, Celso. Cultura e Desenvolvimento em época de crise. Rio de Janeiro: Paz e Terra, 1984.

GOVERNO FEDERAL. As metas do plano nacional de cultura. Ministério da Cultura: Brasília, 2012.

IPEA. Cultura Viva: Avaliação do programa arte educação e cidadania. $1^{\mathrm{a}}$ ed. Brasília: IPEA, 2010.

IPEA. Pontos de cultura: olhares sobre o Programa Cultura Viva / organizadores: Frederico Barbosa, Lia Calabre, Brasília: Ipea, 2011.

IPEA. Resultados dos Redesenho do Programa Cultura Viva. Brasília, 2012. 
MARX, Karl. A questão judaica. In: Manuscritos econômico filosóficos. Tradução de Artur Morão. Lisboa: Edições 70, 1989.

MARX, Karl. Crítica a filosofa do direito de Hegel. Lisboa. Editorial Estampa: 1983.

RUBIM, Antonio Albino Canelas. As políticas culturais e o governo Lula. $1^{\mathrm{a}}$ ed. São Paulo: Fundação Perseu Abramo, 2011.

TAYLOR, Charles. Fuentes del yo: La construccion de la identidad moderna. Barcelona, 2006.

\title{
PUBLIC POLICIES AND CULTURAL AGENTS: AN ANALYSIS OF PROGRAM THE LIVING CULTURE AND THE CULTURE OF POINTS OF THE PARANÁ
}

\begin{abstract}
This research aims to examine the extent to which cultural awareness imposed by the government led to the development of the cultural field configured from the Cultura Viva program. That is, from semi-structured interviews with agents of seven municipalities of Paraná organizations, we seek to understand the relationship between government and ten civil society organizations as contemplated Culture Points in the period 2005 to 2013 , analyzing the impact of this cultural policy in cultural practices, institutional relations, as well as the production and financing of various cultural associations. It also seeks to understand the reflections of a set of cultural agents on the management of Living Culture program and the public cultural policies.
\end{abstract}

Keywords: Cultural agents. Culture Points of Paraná. Living Culture program. Public cultural policies. 